\title{
1 The oddity effect drives prey choice but not necessarily attack time
}

2 Running head: Choice and speed in the oddity effect

3

4 lestyn L. Penry-Williams ${ }^{1 *}$, Christos C. Ioannou ${ }^{2}$, Martin I. Taylor ${ }^{1}$

$5{ }^{1}$ School of Biological Sciences, University of East Anglia, Norwich, United Kingdom

$6{ }^{2}$ School of Biological Sciences, University of Bristol, Bristol, United Kingdom

7

8

*Correspondence to: iestynpw@yahoo.com

9

10

11 Acknowledgements

12 We thank the University of East Anglia for the purchase of materials under the Ecology Research

13 Project Module (BIO-6022Y). CCI was supported by a NERC Independent Research Fellowship

$14 \quad \mathrm{NE} / \mathrm{K} 009370 / 1$ 
Abstract

The tendency of predators to preferentially attack phenotypically odd prey in groups (the oddity effect) is a clear example of how predator cognition can impact behaviour and morphology in prey. Through targeting phenotypically odd prey, predators are thought to avoid the cognitive constraints that delay and limit the success of attacks on homogenous prey groups (the confusion effect). In addition to influencing which prey a predator will attack, the confusion and oddity effects would also predict that attacks on odd prey can occur more rapidly than attacking the majority prey type, as odd prey are more easily targeted, but this prediction has yet to be tested. Here, we used kerri tetra fish, Inpaichthys kerri, presented with mixed phenotypic groups of Daphnia dyed red or black to investigate whether odd prey in groups are preferentially attacked, and whether these attacks were faster than those on the majority prey type. In agreement with previous work, odd prey were targeted and attacked more often than expected from their frequency in the prey groups, regardless of whether the odd prey was red in a group of black prey, or vice versa. However, no difference was found in the time taken to attack odd versus majority prey items, contrary to our predictions. Our results suggest that the time taken to make an attack is determined by a wider range of factors or is subject to greater variance than the choice of which prey is selectively targeted in a group. 


\section{Introduction}

Predation is believed to be a major driver of group formation in prey species across a wide range of taxa (Ioannou, 2017). The tendency to aggregate into social groupings has been observed after both short (Hoare, Couzin, Godin, \& Krause, 2004) and long term (Herbert-Read et al., 2017) exposure to an increased level of predation risk. Correspondingly, individuals in groups often experience higher survival rates compared to solitary individuals (Cresswell, 1994; Neill \& Cullen, 1974; Santos et al., 2016; Treherne \& Foster, 1982). A number of mechanisms act to reduce this per capita risk of predation, including risk dilution (Foster \& Treherne, 1981; Turner \& Pitcher, 1986), the group vigilance effect (Elgar, 1989; Treherne \& Foster, 1981), the avoidance effect (Ioannou, Bartumeus, Krause, \& Ruxton, 2011) and predator mobbing (Andersson \& Wiklund, 1978).

Another widespread mechanism for reducing predation risk in prey groups is the confusion effect, whereby the greater number of targets present in a prey group causes difficulty in the predator's targeting and capture of a single individual (Ioannou, Tosh, Neville, \& Krause, 2008; Krakauer, 1995). This is believed to be due to the sensory overload caused by many (often moving) targets within the visual field, an explanation that has been supported with neural network models (Krakauer, 1995; Tosh, Jackson, \& Ruxton, 2006). The confusion effect has been documented in a wide range of taxa, including fish, bird, cephalopod and human predators (Cresswell, 1994; Landeau \& Terborgh, 1986; Neill \& Cullen, 1974; Schradin, 2000; Theodorakis, 1989; Tosh et al., 2006). Although the formation of groups frequently reduces predation risk in prey, there are numerous mechanisms by which predators have adapted to minimise the effects of, or even to take advantage of, social behaviour in prey. Aggregation can, in some circumstances, increase risk for prey species hunted by predators with the ability to consume multiple prey in a single encounter (Turner \& Pitcher, 1986), such as filter feeders (Rieucau, Fernö, loannou, \& Handegard, 2015; Rode et al., 2013), or those that set traps for collectively foraging prey (Bauer, Federle, Seidel, Grafe, \& Ioannou, 2015). In order to alleviate the confusion effect, predators can reduce vigilance for their own predators, allowing increased attention for prey capture but increasing their own risk of 
predation (Milinski, 1984), target the edges of prey groups where prey may be less dense (Duffield \& loannou, 2017), or selectively target phenotypically odd individuals within the prey group, which stand out from the 'background' of other, homogenous group members. This 'oddity effect' has been demonstrated among predatory fish targeting grouped prey of mixed colours (Landeau \& Terborgh, 1986; Ohguchi, 1978), body size (Rodgers, Downing, \& Morrell, 2015; Theodorakis, 1989) and species (Almany, Peacock, Syms, McCormick, \& Jones, 2007). The strategy of initially focusing on conspicuously odd individuals in dense prey aggregations can be predicted from the optimal foraging theory (Emlen, 1966; MacArthur \& Pianka, 1966; Schoener, 1971), acting to maximise intake of energy per unit time while minimising the time required to obtain energy, which may be slowed by sensory confusion (Almany et al., 2007; Milinski \& Heller, 1978). As a result, this frequencydependent selection against rare phenotypes within groups is often used to explain non-random assortment in groups based on such phenotypic traits (Allan \& Pitcher, 1986; Hoare, Krause, Peuhkuri, \& Godin, 2000; McRobert \& Bradner, 1998). Landeau \& Terborgh (1986) demonstrated an increased attack rate and higher rate of capture when odd individuals were present in groups of silvery minnows (Hybognathus nuchalis) predated by largemouth bass (Micropterus salmoides) compared to homogeneous prey groups. Additionally, investigations on group predation have found shorter capture times for individual prey items than for grouped prey for both leopard geckos (Eublepharis macularius) and common marmosets (Callithrix jacchus) (Schradin, 2000), as well as an increased capture/contact ratio for cephalopod and fish predators (Neill \& Cullen, 1974).

Through focusing attacks on phenotypically odd individuals to minimise the confusion effect, the time required to target and successfully attack a prey item should be reduced, maximising predation efficiency (Landeau \& Terborgh, 1986). Here, a system of artificially coloured Daphnia (Ohguchi, 1978) preyed upon by the predatory fish kerri tetra, Inpaichthys kerri, was used to test whether minority (odd) prey are selectively targeted by predators, as documented in previous experiments, and also the time taken to do so. Therefore, we tested whether the targeting of odd 
prey can occur faster compared to attacks on majority prey phenotypes within the group, following the expected effects of confusion and oddity.

\section{Methods}

\subsection{Predatory fish}

In this study, an experimental predator-prey system was used, consisting of a kerri tetra predating upon mixed phenotypic groupings of Daphnia magna. Kerri tetra are native to South America (Aripuanã River and upper Madeira River basin, Mato Grosso State, Brazil) and are often kept in aquaria. Tetra maintain an omnivorous diet, consisting of detritus plant material as well as live foods including small crustaceans including Artemia and Daphnia spp. Thirty-five mixed-sex kerri tetra 'Super Blue' were sourced from an aquarium wholesaler and were housed in $35 \mathrm{~L}$ aquaria $(31 \times 31 \mathrm{x}$ $37 \mathrm{~cm}$ ) in groups of approximately nine individuals. A natural light cycle was present in the room with additional illumination of tanks from above by a 60 -watt bulb. Water temperature was at $24^{\circ} \mathrm{C}$ and ad libitum feeding of Aqua One Brand tropical fish flakes and Daphnia magna was undertaken prior to the study period. During the predation trial period, fish were not fed for 17 hours prior to their trial.

\subsection{Daphnia prey}

Live Daphnia magna were obtained from Notcutts Garden Centres Ltd., Norwich, and housed in a large indoor container $(47 \times 61 \times 61 \mathrm{~cm}, \sim 175 \mathrm{~L})$ to establish a source population. Daphnia were fed on a mixture of live Spirulina sp., yeast (Fast Action Dried; The Pantry, Aldi) and crushed fish flakes (Aqua One Brand). Daphnia were kept under the optimum conditions as described by Jonczyk and Gilron (2005), of $\sim 20^{\circ} \mathrm{C}$ and a cycle of 16 hours light to 8 hours dark.

To manipulate prey appearance, live Daphnia were dyed red or black using food colouring. Individuals were pipetted into $10 \mathrm{ml}$ beakers; each contained $2 \mathrm{ml}$ of tank water and $0.25 \mathrm{ml}$ of dye for a period of 30 minutes. The dyes (Sainsbury's Brand) ingredients consisted of: Red (Water, Colours: 
Anthocyanins, Paprika Extract; Emulsifier: Polysorbate 80; Acidity Regulator: Citric Acid;

Antioxidants: Alphatocopherol, Ascorbyl Palmitate; Palm Oil, Preservative: Potassium Sorbate) and Black (Propylene Glycol, Water, Colour: Vegetable Carbon; Emulsifier: Acacia Gum; Preservative: Potassium Sorbate; Acidity Regulator: Citric Acid).

\subsection{Preference Tests}

All prey targeting experiments were carried out in tanks of the same dimensions as those housing the fish (i.e. $31 \times 31 \times 37 \mathrm{~cm}, \sim 35 \mathrm{~L}$ ). The trial tank was positioned adjacent (without a gap) to another tank housing approximately nine kerri tetras from the population, to reduce acclimatisation time and stress caused to individuals due to the shoaling behaviour demonstrated in this family (Marcos Mirande, 2009). A single fish was introduced to the trial tank from the stock population, and after an acclimatisation period of 10 minutes the Daphnia group was poured in gently at the surface of the water. The time taken to make the first attack from the introduction of the prey was recorded from observations $\sim 40 \mathrm{~cm}$ from the tank, along with the colour of the prey attacked. Preliminary testing was carried out to determine any preference in the predators for either colour of prey item. Ten kerri tetras were randomly selected from the population and individually presented with ten Daphnia, in an equal ratio of black and red (5:5). A second preliminary preference test was also carried out, with five Daphnia of a single colour presented in each trial for a random sample of 20 predators ( $n=10$ per prey colour).

\subsection{Oddity Trials}

132 Trials testing for the oddity effect used the same protocol as detailed in 2.3, above, with ten Daphnia 133 poured at the surface. Each predator $(n=35)$ was subjected to the following treatments in a random 134 order to reduce order effects over a series of weeks, with a minimum of 48 hours between an 135 individual's trials: Red oddity (Red $1: 9$ Black), black oddity (Black $1: 9$ Red) and in equal ratio (Red 5 : 5 Black). 

consumed) was again recorded, along with the colour of the attacked prey. If a second attack was made within three minutes of the first attack, the time taken (from the first attack) and the colour of the second attacked prey was also recorded. Trials were stopped after 3 minutes if there had been no attacks to ensure prey aggregation. Any fish from trials resulting in no predation were moved into a separate stock tank and the trial was repeated 24 hours later. Variation in extraneous variables was kept to a minimum by carrying out trials during the same hours each day (10am - 3pm) and keeping noise to a minimum. Filters were turned off in the trial tank during trials to avoid distraction and maintain the aggregation of Daphnia prey groups. Any remaining Daphnia were removed from Supplementary Information data.

\subsection{Statistical Analysis}

As the identities of individual fish could not be recorded between trials across treatments, each prey treatment was analysed separately to avoid pseudoreplication within the analysis, as each fish was used only once per prey treatment. Whether the fish showed a preference for a particular prey type (red prey in the equal ratio treatment or odd prey in the odd : majority prey treatments) was tested using binomial tests. The proportion of that prey type in the Daphnia group was used as the The dispersion parameter was inspected to ensure it was approximately equal to 1 (0.5 to 2 ). All statistical tests were carried out in $\mathrm{R}$ version 3.3.3 (R Development Core Team, 2011). 
the time taken to make an attack, we carried out a randomisation-based power analysis to determine approximately how many trials would be required to achieve a statistically significant effect of target prey colour on the time taken. The observed data was resampled with replacement $N$ times, and the negative binomial GLMs as described above were repeated on this randomly sampled data. $N$ is the simulated sample size, and we tested sample sizes from 40 to 1,000 trials in increments of 10 trials. At each value of $N, 1,000$ iterations were carried out and the $\mathrm{P}$ value associated with the effect of prey colour (from the negative binomial GLMs) at the $80 \%$ quantile was saved for each value of $N$. This $80 \%$ corresponds to a value of beta of 0.8, where beta is the test power to avoid incorrectly accepting the null hypothesis. Reported is the sample size $(N)$ where the $\mathrm{P}$ value at the $80 \%$ quantile is statistically significant at $P<0.05$; in other words, the sample size that is expected to be required to detect a statistically significant difference in $80 \%$ of repeats of the experiment.

\section{Results}

\subsection{Prey colour preference}

In the first preliminary test with homogenous groups of 5 prey items, no evidence to support faster targeting based purely on colour alone was found. There was no significant difference in the time from introduction to first attack between the two colours (mean \pm SD, Black: $13.17 \pm 7.02 \mathrm{~s}$ and Red: $10.02 \pm 6.55 \mathrm{~s}$, negative binomial GLM: deviance $=1.059, \mathrm{P}=0.30)$. In the second preliminary test with a ratio of 5 red to 5 black Daphnia per trial, there was no evidence of selective predation based on colour. Each prey type was targeted and attacked in the first attack in exactly the same ratio that would be expected from random predation, with each colour being targeted in $50 \%$ of trials. There was also no significant difference in the time taken from prey introduction to attack between the prey colour conditions (mean \pm SD, Black: $8.92 \pm 5.29$ s and Red: $5.78 \pm 1.91 s$, Welch Two Sample t-test: $t=1.2503, d f=5.0234, p=0.2663)$. 

the proportion of red prey targeted in the first attack (15/35 trials) did not vary significantly from random targeting (Figure $1 \mathrm{~A}$, binomial test: $\mathrm{P}=0.50$ ). In the 30 trials of this treatment where a second attack also took place, there was a tendency for the red prey to be attacked ( 20 trials), although this effect was not significantly different to that expected from chance alone (Figure 1B, binomial test: $P=0.099$; the expected probability of attacking red prey was calculated from the proportions of red to black prey remaining after the first attack in these trials), providing further evidence in support of no selective predation based on colour alone.

\subsection{Selection for prey oddity}

Of first attacks in the 35 trials, 11 trials resulted in the odd prey being targeted when the odd prey was red ( 1 red : 9 black), and the same number of trials resulted in the odd prey being targeted when the odd prey was black ( 1 black : 9 red). This proportion (31\%) was significantly greater than that expected from random targeting (binomial test: $\mathrm{P}=0.00042$ ), given the proportion of odd to majority prey (10\%). There was thus evidence of an oddity effect in both treatments, seemingly unaffected by whether the odd prey item was red or black.

The oddity effect was also evident in the second attack made, excluding trials where the first attack resulted in the odd prey being consumed as there was no odd prey present in the second attack, thus changing the expected ratio from random predation (1 odd : 8 majority prey). In 8 out of 24 trials the targeted prey was odd when it was red (binomial test: $P=0.0033$ ), and 8 out of 22 trials the targeted prey was odd when it was black (binomial test: $P=0.0018$ ). Overall, in each of the oddity treatments, 19 of the 35 trials resulted in an odd prey being consumed during either the first or second predation event, regardless of whether the odd prey was red or black (Figure 1).

\subsection{Time taken to attack prey}


No correlation was found between the time for the first and second attack within any treatment

(Figure 2, Spearman's rank correlation: equal ratio treatment: $r_{s}=0.29, P=0.12$; red odd treatment: $r_{s}=-0.095, P=0.59 ;$ black odd treatment: $\left.r_{s}=0.12, P=0.51\right)$. This indicates that the two latencies were likely driven by different factors; the first and second attacks of each treatment were therefore analysed separately. For the first attack by each fish, attacks on odd prey were not more or less rapid than attacks on majority prey (negative binomial GLM: red odd treatment: deviance $=0.20, P=0.65$; black odd treatment: deviance $=1.11, P=0.29)$. The power analysis revealed sample sizes of $>1,000$ and 230 trials for red odd and black odd treatments, respectively, would be required to reliably detect a statistically significant effect. Similarly, there was no difference in the time taken to make the second attack depending on whether the second attacked prey was odd or in the majority (red odd treatment: deviance $=0.00092, \mathrm{P}=0.98$; black odd treatment: deviance $=0.0034, \mathrm{P}=0.95)$. Sample sizes of $>1,000$ were estimated to be required to detect statistically significant effects in both tests.

The time taken to make the second attack was also analysed as a function of whether the prey group still contained an odd prey (in trials where a majority prey was attacked first) or was homogeneous with only the majority prey type remaining (in trials where an odd prey was attacked first). In the red odd treatment, there was no indication that the presence of an odd prey in the second attack affected the time taken to make the attack (negative binomial GLM: deviance $=0.026$, $P=0.87)$. However, the presence of a black odd prey made the time taken to attack the second prey significantly faster than if the prey group was homogenously red (deviance $=4.81, P=0.028$ ). This finding supports that of Landeau \& Terborgh (1986) who also demonstrated that attacks on groups containing phenotypically odd prey were faster than those on homogeneous groups. time taken to attack each prey type (Figure 3, negative binomial GLM: first attack: deviance $=0.13, \mathrm{P}$ $=0.72$, second attack: deviance $=2.00, P=0.16)$, further supporting the finding that there was no 
required to detect a statistically significant effect of prey colour for first and second attacks, respectively.

\section{Discussion}

In agreement with previous studies, mostly in fish (Almany et al., 2007; Landeau \& Terborgh, 1986; Ohguchi, 1978; Rodgers et al., 2015; Theodorakis, 1989), we demonstrate a strong oddity effect in the kerri tetra predating artificially coloured Daphnia prey. There was no apparent preference for red or black coloured prey, but when the oddly coloured phenotype in a group was dominated by the other colour, both red and black coloured prey were attacked in a significantly greater proportion than expected from their frequency in the group. This frequency-dependent predation selects against rare phenotypes in prey groups, and provides a mechanism for prey groups to assort and be homogenous (Allan \& Pitcher, 1986; Hoare et al., 2000; McRobert \& Bradner, 1998). The most widely accepted explanation for the oddity effect is that predators find it less cognitively demanding to attack prey that are visually different than others present in the group, where multiple prey in the visual field cause the confusion effect (loannou et al., 2008). Based on this cognitive explanation, we predicted that in addition to a preference for attacking phenotypically odd individuals, attacks on these prey should take less time because these prey are more quickly targeted, and should be easier to attack once a target prey is selected (compared to a non-odd, majority prey item). However, we found no evidence that attacks on odd prey were faster than those on majority prey items when attacks were made on groups with an odd individual. Attacks were faster, however, when the second attack was made on a group with the odd black prey remaining compared to a homogenous group of red prey, in which the odd prey had already been consumed (as previously demonstrated by Landeau \& Terborgh, 1986). However, this was not consistently demonstrated, with no evidence presented when comparing groups containing odd red prey and homogenously black groups in the second attack. 
The time taken to complete cognitively demanding tasks is a widespread method used to measure the difficulty of a task in both cognitive psychology (Hockley, 1984; Wenger \& Townsend, 2000) and animal behaviour (Abbott \& Sherratt, 2013; Passino \& Seeley, 2006). It is thus surprising to find that a preference for odd prey exists but no evidence of any effect of the targeted prey type on the time taken in this study. Previous work, also using Daphnia as prey, has shown a reduced rate of attacks on larger groups (Ioannou et al., 2008; Milinski, 1977), suggesting that the confusion effect does indeed slow the speed at which attacks are made (although see Duffield \& loannou, 2017, using virtual prey). Previous work using bluegill sunfish (Lepomis macrochirus) attacking a virtual prey population (Ioannou, Guttal, \& Couzin, 2012) has shown a similar trend, where differences in the time taken to make an attack could not explain the predators' avoidance of polarised prey groups. Similarly, despite evolving the prey behaviours to create a population with fewer of the prey types There are a number of possible explanations for why the time taken to make an attack may not reflect prey phenotypes presented or selected for attack. One explanation is that the time taken to identify prey and make attacks tend to be highly variable (e.g. Figure 3 ), suggesting that interindividual response varies greatly between trials, even when the prey group composition is the same within each treatment. Similar results were found in Neill \& Cullen's (1974) study investigating cephalopod and fish hunting behaviour, noting that there was a great deal of variation in the time for predators to make initial contact with prey. This could be due to consistent behavioural differences between individual fish, i.e. animal 'personality'. Consistent variation in boldness (the response to perceived risk: Réale, Reader, Sol, McDougall, \& Dingemanse, 2007) has been shown to correlate with the latency to approach and consume food (loannou \& Dall, 2016). Mamuneas et al. (2014) showed bolder (typically male) three-spined sticklebacks (Gasterosteus aculeatus) to have faster information acquisition and decision making ability (determined from maze navigation to a food reward) than shyer conspecifics, but demonstrated no difference in decision-making accuracy. 
(McDonald, Rands, Hill, Elder, \& loannou, 2016). Although such differences in motivation can often result in inter-trial variation that swamps any other measured effect such as the prey phenotype targeted (e.g. odd or majority). Our study showed no relationship between the time taken to attack the first prey from when the prey were introduced and the time taken to attack the second prey after the first prey was consumed (shown in Figure 2). This suggests that factors other than motivation drove the time taken to attack the first and second prey within the trials. The delay from the introduction of prey to the first attack may be primarily affected by the time needed to detect, recognise and decide to attack the prey, while the second attack should be predominantly influenced by the decision to attack another prey, given the level of perceived risk by the predator (Lima \& Dill, 1990). confusion to generate a difference between odd and majority prey in the time taken to make the attack (although the task did affect prey choice). The predation of Daphnia by aquatic predators has been prevalent in the literature on confusion and oddity (e.g. Landeau \& Terborgh, 1986; Milinski, 1977; Rodgers et al., 2015). Previous studies utilising a similar methodology have determined an increasing level of confusion with increasing group numbers. Landeau and Terborgh (1986) demonstrated an increased level of difficulty in prey capture in any group larger than one individual. The greatest level of difficulty was demonstrated in the larger groups of 8 and 15 individuals, with only $17 \%$ and $11 \%$ of the trials resulting in capture, respectively, and an increased number of attacks per kill. While tests into size oddity by Rodgers et al. (2015) utilised 12 individuals per group. Therefore, with reflective groups sizes present within our study ( $n=10$ per trial), it can be assumed that the confusion effect was present. Interestingly our results and those from other studies suggests that the time taken to make an attack may be more variable and hence less predictable than the choice of which prey to target. To the best of our knowledge, this issue has not been explicitly investigated in previous studies on 
predator-prey interactions. It may suggest however that selection pressure from predator behaviour is asymmetric, with strong selection on prey phenotypes from predators' choice of which prey to attack, but relatively weak selection on predators being able to make faster attacks when attacking particular prey types. If this is the case, it brings into question why predators show such preferences for these odd individuals. It may be that a reduction in the time taken to initiate own predators, which may apply a stronger selective pressure (e.g. Milinski, 1984).

\section{References}

Abbott, K. R., \& Sherratt, T. N. (2013). Optimal sampling and signal detection: unifying models of attention and speed-accuracy trade-offs. Behavioral Ecology, 24(3), 605-616. https://doi.org/10.1093/beheco/art001

Allan, J. R., \& Pitcher, T. J. (1986). Species segregation during predator evasion in cyprinid fish shoals. Freshwater Biology, 16(5), 653-659. https://doi.org/10.1111/j.1365-2427.1986.tb01007.x

Almany, G. R., Peacock, L. F., Syms, C., McCormick, M. I., \& Jones, G. P. (2007). Predators target rare prey in coral reef fish assemblages. Oecologia, 152(4), 751-761. https://doi.org/10.1007/s00442-007-0693-3

Andersson, M., \& Wiklund, C. G. (1978). Clumping versus spacing out: Experiments on nest predation in fieldfares (Turdus pilaris). Animal Behaviour, 26, 1207-1212. https://doi.org/10.1016/00033472(78)90110-0

Bauer, U., Federle, W., Seidel, H., Grafe, T. U., \& loannou, C. C. (2015). How to catch more prey with less effective traps: explaining the evolution of temporarily inactive traps in carnivorous pitcher plants. Proceedings of the Royal Society B: Biological Sciences, 282(1801), 20142675. https://doi.org/10.1098/rspb.2014.2675

Cresswell, W. (1994). Flocking is an effective anti-predation strategy in redshanks, Tringa totanus. 
Duffield, C., \& loannou, C. C. (2017). Marginal predation: Do encounter or confusion effects explain the targeting of prey group edges? Behavioral Ecology, 28(5), 1283-1292. https://doi.org/10.1093/beheco/arx090

Elgar, M. A. (1989). Predator vigilance and group size in mammals and birds: a critical review of the empirical evidence. Biological Reviews, 64(1), 13-33. http://dx.doi.org/10.1111/j.1469185X.1989.tb00636.x

Emlen, J. M. (1966). The role of time and energy in food preference. The American Naturalist, 100(916), 611-617. https://doi.org/10.1086/282455

Foster, W. A., \& Treherne, J. E. (1981). Evidence for the dilution effect in the selfish herd from fish predation on a marine insect. Nature, 293(5832), 466-467. https://doi.org/10.1038/293466a0

Herbert-Read, J. E., Rosén, E., Szorkovszky, A., loannou, C. C., Rogell, B., Perna, A., ... Sumpter, D. J. T. (2017). How predation shapes the social interaction rules of shoaling fish. Proceedings of the Royal Society B: Biological Sciences, 284(1861), 20171126. https://doi.org/10.1098/rspb.2017.1126

Hoare, D. J., Couzin, I. D., Godin, J. G. J., \& Krause, J. (2004). Context-dependent group size choice in fish. Animal Behaviour, 67(1), 155-164. https://doi.org/10.1016/j.anbehav.2003.04.004

Hoare, D. J., Krause, J., Peuhkuri, N., \& Godin, J.-G. J. (2000). Body size and shoaling in fish. Journal of Fish Biology, 57(6), 1351-1366. https://doi.org/10.1111/j.1095-8649.2000.tb02217.x

Hockley, W. E. (1984). Analysis of response time distributions in the study of cognitive processes. Journal of Experimental Psychology: Learning, Memory, and Cognition, 10(4), 598-615. https://doi.org/10.1037/0278-7393.10.4.598

loannou, C. C. (2017). Grouping and Predation. In T. K. Shackelford \& V. A. Weekes-Shackelford (Eds.), Encyclopedia of Evolutionary Psychological Science (pp. 1-6). Cham: Springer International Publishing. https://doi.org/10.1007/978-3-319-16999-6_2699-1

Ioannou, C. C., Bartumeus, F., Krause, J., \& Ruxton, G. D. (2011). Unified effects of aggregation reveal 
larger prey groups take longer to find. Proceedings of the Royal Society B: Biological Sciences, 278, 2985-2990. https://doi.org/10.1098/rspb.2011.0003

Ioannou, C. C., \& Dall, S. R. X. (2016). Individuals that are consistent in risk-taking benefit during collective foraging. Scientific Reports, 6, 33991. https://doi.org/10.1038/srep33991

Ioannou, C. C., Guttal, V., \& Couzin, I. D. (2012). Predatory fish select for coordinated collective motion in virtual prey. Science, 337(6099), 1212-1215.

Ioannou, C. C., Tosh, C. R., Neville, L., \& Krause, J. (2008). The confusion effect - from neural prospectus. Canadian Journal of Zoology, 68(4), 619-640. https://doi.org/10.1139/z90-092

MacArthur, R. H., \& Pianka, E. R. (1966). On optimal use of a patchy environment. The American Naturalist, 100(916), 603-609. https://doi.org/10.1086/282454

Mamuneas, D., Spence, A. J., Manica, A., \& King, A. J. (2014). Bolder stickleback fish make faster decisions, but they are not less accurate. Behavioral Ecology, 26(1), 91-96. https://doi.org/10.1093/beheco/aru160

Marcos Mirande, J. (2009). Weighted parsimony phylogeny of the family Characidae (Teleostei: Characiformes). Cladistics, 25(6), 574-613. https://doi.org/10.1111/j.1096-0031.2009.00262.x 
McDonald, N. D., Rands, S. A., Hill, F., Elder, C., \& loannou, C. C. (2016). Consensus and experience trump leadership, suppressing individual personality during social foraging. Science Advances, 2(9), e1600892. https://doi.org/10.1126/sciadv.1600892

McRobert, S. P., \& Bradner, J. (1998). The influence of body coloration on shoaling preferences in fish. Animal Behaviour, 56(3), 611-615. https://doi.org/https://doi.org/10.1006/anbe.1998.0846

Milinski, M. (1977). Experiments on the selection by predators against spatial oddity of their prey. Zeitschrift Für Tierpsychologie, 43(3), 311-325. https://doi.org/10.1111/j.14390310.1977.tb00078.x

Milinski, M. (1984). A predator's costs of overcoming the confusion-effect of swarming prey. Animal Behaviour, 32(4), 1157-1162. https://doi.org/10.1016/S0003-3472(84)80232-8

Milinski, M., \& Heller, R. (1978). Influence of a predator on the optimal foraging behaviour of sticklebacks (Gasterosteus aculeatus L.). Nature, 275(5681), 642-644. http://dx.doi.org/10.1038/275642a0

Neill, S. R. J., \& Cullen, J. M. (1974). Experiments on whether schooling by their prey affects the hunting behaviour of cephalopods and fish predators. J. Zool. Lond, 172(54), 569. http://dx.doi.org/10.1111/j.1469-7998.1974.tb04385.x

Ohguchi, O. (1978). Experiments on the selection against colour oddity of water fleas by threespined sticklebacks. Zeitschrift Für Tierpsychologie, 47(3), 254-267. https://doi.org/10.1111/j.1439-0310.1978.tb01835.x

Passino, K., \& Seeley, T. (2006). Modeling and analysis of nest-site selection by honeybee swarms: the speed and accuracy trade-off. Behavioral Ecology and Sociobiology, 59(3), 427-442. https://doi.org/10.1007/s00265-005-0067-y

R Development Core Team. (2011). R: A language and environment for statistical computing. Vienna. http://www.r-project.org: R Foundation for Statistical Computing. Retrieved from http://www.r-project.org 
Réale, D., Reader, S. M., Sol, D., McDougall, P. T., \& Dingemanse, N. J. (2007). Integrating animal temperament within ecology and evolution. Biological Reviews, 82(2), 291-318. https://doi.org/10.1111/j.1469-185X.2007.00010.x

Rieucau, G., Fernö, A., loannou, C. C., \& Handegard, N. O. (2015). Towards of a firmer explanation of large shoal formation, maintenance and collective reactions in marine fish. Reviews in Fish Biology and Fisheries, 25(1). https://doi.org/10.1007/s11160-014-9367-5

Rode, N. O., Lievens, E. J. P., Flaven, E., Segard, A., Jabbour-Zahab, R., Sanchez, M. I., \& Lenormand, T. (2013). Why join groups? Lessons from parasite-manipulated Artemia. Ecology Letters, 16(4), 493-501. https://doi.org/10.1111/ele.12074

Rodgers, G. M., Downing, B., \& Morrell, L. J. (2015). Prey body size mediates the predation risk associated with being "odd." Behavioral Ecology, 26(1), 242-246. https://doi.org/http://dx.doi.org/10.1093/beheco/aru185

Santos, R. G., Pinheiro, H. T., Martins, A. S., Riul, P., Bruno, S. C., Janzen, F. J., \& loannou, C. C. (2016). The anti-predator role of within-nest emergence synchrony in sea turtle hatchlings. Proceedings of the Royal Society of London B: Biological Sciences, 283(1834), 20160697. https://doi.org/10.1098/rspb.2016.0697

Schoener, T. W. (1971). Theory of feeding strategies. Annual Review of Ecology and Systematics, 2(1), 369-404. https://doi.org/10.1146/annurev.es.02.110171.002101

Schradin, C. (2000). Confusion effect in a reptilian and a primate predator. Ethology, 106(8), 691700. https://doi.org/10.1046/j.1439-0310.2000.00582.x

Theodorakis, C. W. (1989). Size segregation and the effects of oddity on predation risk in minnow schools. Animal Behaviour, 38(3), 496-502. https://doi.org/10.1016/s0003-3472(89)80042-9

Tosh, C. R., Jackson, A. L., \& Ruxton, G. D. (2006). The confusion effect in predatory neural networks. The American Naturalist, 167(2), E52-E65. https://doi.org/10.1086/499413

Treherne, J. E., \& Foster, W. A. (1981). Group transmission of predator avoidance behaviour in a marine insect: The Trafalgar effect. Animal Behaviour, 29(3), 911-917. 
447 Treherne, J. E., \& Foster, W. A. (1982). Group size and anti-predator strategies in a marine insect.

448 Animal Behaviour, 30(2), 536-542. https://doi.org/10.1016/S0003-3472(82)80066-3

449 Turner, G. F., \& Pitcher, T. J. (1986). Attack abatement: a model for group protection by combined

450 avoidance and dilution. American Naturalist, 128(2), 228-240. https://doi.org/10.1086/284556

451 Wenger, M. J., \& Townsend, J. T. (2000). Basic response time tools for studying general processing

452 capacity in attention, perception, and cognition. The Journal of General Psychology, 127(1), 67-

$453 \quad 99$. https://doi.org/10.1080/00221300009598571

454

455 
Figure 1: The frequency (total counts) of attacking each prey type (red or black) in the three different treatments (equal ratio, red odd prey and black odd prey) for the first (a) and second (b) attack in each trial. First attack: All treatments ( $n=35$ trials), Second attack: Equal ratio ( $n=30$ trials), red oddity ( $n=24$ trials) and black oddity ( $n=22$ trials). Trials are omitted from the second attack plot (and corresponding analysis) if the first attack was on the odd prey, as only majority prey type remained. Expected frequencies of attacking each prey colour, based on the frequency of each colour within the trials, is indicated by the horizontal dashed lines.

Figure 2: The correlation between the times (seconds) taken to attack the first and second prey in each trial. The data are arranged by treatment: equal ratio (a), red odd prey (b) and black odd prey (c). First attack: All treatments ( $n=35$ trials), Second attack: Equal ratio $(n=30$ trials), red oddity $(n=$ 24 trials) and black oddity ( $n=22$ trials).

470

Figure 3: The time (seconds) taken to make the first (a) and second (b) attack in each treatment. Attacks are split within each treatment depending on prey type. First attack: All treatments $(n=35$ trials), Second attack: Equal ratio ( $n=30$ trials), red oddity $(n=34$ trials) and black oddity $(n=33$ trials). Medians are illustrated by thick horizontal lines (black or white), the interquartile range (IQR) is enclosed within the boxes and the whiskers represent cases within $1.5 \times$ IQR. The empty circles represent data points outside of the whiskers. 